\title{
Oral Health - Related Quality of Life of Periodontal Patients in a Syrian Sample - A Pilot Study
}

\section{Dannan $\mathrm{A}^{* 1}$ and Joumaa $\mathrm{A}^{2}$}

${ }^{1}$ Department of Periodontology, Faculty of Dentistry, Syrian Private University, Damascus, Syria ${ }^{2}$ Research award competition, Faculty of Dentistry, Syrian Private University, Damascus, Syria

*Corresponding author: Dannan A, Department of Periodontology, Faculty of Dentistry, Syrian Private University, Damascus, Syria, E-mail: aousdannan@yahoo.com

Citation: Dannan A, Joumaa A (2015) Oral Health - Related Quality of Life of Periodontal Patients in a Syrian Sample - A Pilot Study. J Dent Oral Care Med 1(1): 103. doi: 10.15744/2454-3276.1.103

Received Date: March 10, 2015 Accepted Date: May 13, 2015 Published Date: May 14, 2015

\begin{abstract}
Objectives: To assess the oral health-related quality of life in a Syrian sample of patients, and to assess the perceived oral health.

Study design: The sample of the study consisted of 36 patients who visited the dental clinic of the Syrian Private University (SPU) seeking dental and/or periodontal treatments. The selected patients completed a modified questionnaire including a single question about the perceived gingival health, and five additional questions representing the impact of periodontal disease on their quality of life. The association between the perceived gingival health and the actual clinical findings of the periodontium was assessed.

Results: About $42 \%$ of the patients diagnosed for chronic gingivitis described their gingival health as "excellent", whereas only $5.2 \%$ described it as "bad". Forty percent of the patients diagnosed for mild chronic periodontitis described their gingival health as "good", and $40 \%$ of them described it as "bad". Twenty-five percent of the patients diagnosed for moderate chronic periodontitis described their gingival health as "very good", whereas $50 \%$ of them described it as "bad". All the patients (100\%) diagnosed for advanced chronic periodontitis described their gingival health as "bad". Pain was mostly mentioned by patients diagnosed for chronic gingivitis, initial chronic periodontitis, and moderate chronic periodontitis. Eating was most affected by the patients diagnosed for advanced chronic periodontitis.

Conclusion: An accepted degree of awareness towards oral health problems related to periodontal disease was noticed in this study, especially by patients diagnosed for advanced chronic periodontitis. Further studies are needed regarding the relationship between oral health-related quality of life and chronic periodontitis.
\end{abstract}

Keywords: Periodontal disease; Oral health; Quality of life

\section{Introduction}

Periodontal disease is a major oral health problem, in which specific species of bacteria play an important role in its progressing and severity. Because chronic periodontitis is believed to be asymptomatic in its initial stages, it has been suggested that individuals may be unaware of their clinical periodontal status [1-3] and underestimate what treatments are required, as judged by dental professionals [4]. In its more advanced stages, chronic periodontitis can be associated with signs and symptoms that are readily perceivable by individuals, such as tooth mobility, pain, eating difficulties, unaesthetic loss of anterior interproximal papillae, or discomfort $[5,6]$.

The severity of periodontal disease is usually documented by research clinicians using clinical parameters such as bleeding on probing (BOP), probing pocket depth (PPD), and clinical attachment level (CAL [7].

However, other symptoms of periodontal disease include the consequences of chronic inflammation and the destruction of toothsupporting tissues, such as redness, bleeding on brushing, loosening of affected teeth, and persistent bad breath. These symptoms are not normally documented in a research report. Such symptoms, however, are highly relevant from the patients' point of view and often have a considerable adverse impact on their daily quality of life (QoL) [8].

A better understanding of the consequences of periodontal disease and its treatment on patients' perceptions of how their oral health affects their daily lives can help to insure that the planning and evaluation of periodontal care and treatment adequately address patients' needs and concerns [9]. The use of patient-centered measures in dentistry is increasing. A number of instruments have emerged with promising psychometric properties.

The aim of this pilot study was to assess the oral health-related quality of life of patients presenting to the open clinics of the Faculty of Dentistry in the Syrian Private University by means of five questions, and to assess the perceived oral health by means of one question. Self-assessments of oral health were associated with clinical characteristics. 


\section{Materials and Methods}

The sample of this study consisted of a group of patients who were referred to the open dental clinics of the Faculty of Dentistry at the Syrian private University seeking periodontal treatments and/or other regular dental treatments. A total number of 36 patients were recruited in the study. A previous approval was obtained from the Research Authority of the University in order to achieve the study, and written consents were collected from the patients who agreed to be part of the study.

A modified questionnaire was given to every patient in the sample before any treatment. This questionnaire included general information about the gender, age, systemic diseases, smoking, as well as a single question that reflected the self-assessment of the gingival health, and five additional questions under separate category expressing the effect of periodontal disease on several daily life activities.

The actual clinical diagnosis of the periodontal health was obtained from the patients' clinical charts that were recorded by the fifth-grade undergraduate students at the Faculty, for whom the patients were presented. In order to minimize the inter-examiner bias, all charts were extensively re-checked by one examiner.

The classification of the American Academy of Periodontology (AAP) for periodontal diseases [10] was used to classify the cases examined. Accordingly, all cases were recorded under one of the following:

Acute or chronic gingivitis

Mild chronic periodontitis (with periodontal pockets 4 - $5 \mathrm{~mm}$ on one or more teeth)

Moderate chronic periodontitis (with periodontal pockets $5-6 \mathrm{~mm}$ on one or more teeth)

Advanced chronic periodontitis (with periodontal pockets $>6 \mathrm{~mm}$ on one or more teeth)

The self-assessment of the gingival health was obtained by means of a single question: "How do you currently express your gingival health?". The answers for this question had to be chosen among the following statements: "excellent, very good, good, fair, poor". All patients who chose "fair" or "poor" were considered to have the worst self-assessment of gingival health.

The effect of periodontal disease on the daily life activities was expressed by means of a simple questionnaire included five questions on the impact on eating, sleep and relaxation, interaction with the society (i.e. society avoidance), anxiety, and pain. The patients had to choose one of the following answers for this question: "never, hardly, occasionally, sometimes, most of times". All patients who answered with "sometimes" or "most of times" were considered to have the most common problems related to the daily life activities. This questionnaire was considered as a modified version of that used by Cunha-cruz et al. in a study conducted in 2007 [11].

The language of all questions in the questionnaires used in our study was Arabic.

\section{Statistical Study}

Descriptive statistical analysis was mainly used in this study by means of a simple computer program (Excel, Office 2010 for Windows). The sample of the study was demonstrated according to the gender, age, smoking, and the existence of systemic diseases, as well as the answers for the self-assessment of the gingival health, and the impact of periodontal disease on the daily life activities. The relationship between the worst gingival status (from the patients' point of view), along with the affected daily life activities, and the actual clinical findings was also demonstrated.

\section{Results}

The patients in the study sample (66.6\% males and 33.3\% females) ranged in age between 15 and 58 years old (Mean 36.5$)$. Only $2.7 \%$ stated they were suffering a kind of diabetes mellitus, and $63.8 \%$ were smokers.

The clinical examination of the patients showed that $52.7 \%$ were suffering chronic gingivitis without attachment loss, and that $27.7 \%$ were suffering mild chronic periodontitis. $11.1 \%$ were suffering moderate chronic periodontitis, and $8.3 \%$ were suffering advanced chronic periodontitis (Table 1).

\begin{tabular}{|c|c|c|c|c|}
\hline $19(52,7 \%)$ & Patients suffering chronic gingivitis & \multirow{2}{*}{$\begin{array}{c}\text { Smokers } \\
23(63,8 \%)\end{array}$} & \multirow{3}{*}{$\begin{array}{c}\text { Males } \\
24(66,6 \%)\end{array}$} & \multirow{5}{*}{$\begin{array}{l}\text { Sample } \\
(36 \mathrm{n}=)\end{array}$} \\
\hline $10(27,7 \%)$ & Patients suffering mild chronic & & & \\
\hline & & \multirow{3}{*}{$\begin{array}{c}\text { Diabetic } \\
\text { patients } \\
1(2,7 \%)\end{array}$} & & \\
\hline $4(11,1 \%)$ & Patients suffering moderate chronic periodontitis & & \multirow{2}{*}{$\begin{array}{c}\text { Females } \\
12(33,3 \%)\end{array}$} & \\
\hline $3(8,3 \%)$ & Patients suffering advanced chronic periodontitis & & & \\
\hline
\end{tabular}

Table 1: Characterization of the sample

\section{Self-assessment of gingival health}

Regarding the gingival health from the patients' point of view, $22.2 \%$ of them mentioned that their gingival health was "excellent", and $19.4 \%$ described their gingival health as "very good", and 30.5\% said it was "good", whereas $11.1 \%$ mentioned that their gingival health was "fair", and $16.6 \%$ of them said their gingival health was "poor". These results means that $27.7 \%$ of the patients described their gingival health as "bad" (Table 2). 


\begin{tabular}{|c|c|c|c|}
\hline \multicolumn{2}{|c|}{ Percentage } & Number & Selected answer \\
\hline \multicolumn{2}{|c|}{$22,2 \%$} & 8 & Excellent \\
\hline \multicolumn{2}{|c|}{$19,4 \%$} & 7 & Very good \\
\hline & $30,5 \%$ & 11 & Good \\
\hline \multirow{2}{*}{$\mathrm{Bad}$} & $11,1 \%$ & 4 & Fair \\
\cline { 2 - 4 }$(27,7 \%)$ & $16,6 \%$ & 6 & Poor \\
\hline
\end{tabular}

Table 2: Patients' answers to the gingival health self-assessment question

Binding the patients' answers for the gingival health self-assessment with their clinical diagnosis and findings, it has been shown that $42.1 \%$ of the patients with chronic gingivitis expressed their gingival health as "excellent", and that $5.2 \%$ of them expressed it as "bad".

Of the patients suffering mild chronic periodontitis, $40 \%$ expressed their gingival health as "good", and $40 \%$ expressed it as "bad". Of the patients suffering moderate chronic periodontitis, 25\% expressed their gingival health as "good", and 50\% expressed it as "bad".

All the patients (100\%) suffering advanced chronic periodontitis expressed their gingival health as "bad" (Table 3 ).

\begin{tabular}{|c|c|c|c|c|c|c|}
\hline \multicolumn{5}{|c|}{ Patients' answers to the self-assessment question } & & \\
\hline Poor & fair & Good & Very good & excellent & & \\
\hline 0 & 1 & \multirow[t]{2}{*}{6} & \multirow[t]{2}{*}{4} & \multirow[t]{2}{*}{$8(42,1 \%)$} & \multirow{2}{*}{ Chronic gingivitis } & \multirow{8}{*}{ Clinical diagnosis } \\
\hline & $(5,2 \%)$ & & & & & \\
\hline $4(40 \%)$ & 0 & \multirow[t]{2}{*}{$4(40 \%)$} & \multirow[t]{2}{*}{2} & \multirow[t]{2}{*}{0} & \multirow{2}{*}{$\begin{array}{l}\text { Mild chronic } \\
\text { periodontitis }\end{array}$} & \\
\hline \multicolumn{2}{|c|}{ Bad $(40 \%)$} & & & & & \\
\hline 0 & $2(50 \%)$ & \multirow[t]{2}{*}{1} & \multirow[t]{2}{*}{1} & \multirow[t]{2}{*}{0} & \multirow{2}{*}{$\begin{array}{l}\text { Moderate chronic } \\
\text { periodontitis }\end{array}$} & \\
\hline \multicolumn{2}{|c|}{$\operatorname{Bad}(50 \%)$} & & & & & \\
\hline 2 & 1 & \multirow[t]{2}{*}{0} & \multirow[t]{2}{*}{0} & \multirow[t]{2}{*}{0} & \multirow{2}{*}{$\begin{array}{l}\text { Advanced chronic } \\
\text { periodontitis }\end{array}$} & \\
\hline \multicolumn{2}{|c|}{$\operatorname{Bad}(100 \%)$} & & & & & \\
\hline
\end{tabular}

Table 3: Patients' answers to the gingival health self-assessment regarding their clinical diagnosis

\section{The effect on daily life activities}

Sleep and relaxation were the least affected by periodontal disease as reported by the patients (61.1\%). On the other side, pain was the most common problem reported (41.5\%), followed by anxiety (27.7\%), avoiding interactions with the society (16.5\%), and eating (13.8\%) (Table 4).

\begin{tabular}{|c|c|c|c|c|c|c|}
\hline \multicolumn{5}{|c|}{ Affected life activity } & & \\
\hline Pain & Anxiety & Society avoidance & Sleep & Eating & & \\
\hline$(36,3 \%) 12$ & $(41,6 \%) 15$ & $(52,7 \%) 19$ & $(61,1 \%) 22$ & $(38,8 \%) 14$ & Never & \multirow{5}{*}{ Answers } \\
\hline$(13,8 \%) 5$ & $(19,4 \%) 7$ & $(19,4 \%) 7$ & $(11,1 \%) 4$ & (25\%) 9 & Hardly & \\
\hline$(11,1 \%) 4$ & $(13,8 \%) 5$ & $(11,1 \%) 4$ & $(13,8 \%) 5$ & $(25 \%) 9$ & Occasionally & \\
\hline$(38,8 \%) 14$ & $(25 \%) 9$ & $(13,8 \%) 5$ & $(5,5 \%) 2$ & $(11,1 \%) 4$ & Sometimes & \\
\hline$(2,7 \%) 1$ & $(2,7 \%) 1$ & $(2,7 \%) 1$ & $(5,5 \%) 2$ & $(2,7 \%) 1$ & Most of times & \\
\hline $41,5 \%$ & $27,7 \%$ & $16,5 \%$ & $11 \%$ & $13,8 \%$ & $\begin{array}{l}\text { Most common (sometimes } \\
+ \text { most of times) }\end{array}$ & \\
\hline
\end{tabular}

Table 4: Affected daily-life activities due to periodontal problems as reported by the patients

Binding the clinical diagnosis and findings of the patients with the affected daily life activities, it has been shown that pain was the most common problem with the patients suffering chronic gingivitis and those who were suffering mild chronic periodontitis ( $21 \%$ and $71 \%$ respectively). Patients suffering moderate chronic periodontitis mostly complained pain and anxiety (50\% for both problems). Finally, $100 \%$ of the patients suffering advanced chronic periodontitis reported that pain and eating were the most common problems affected (Table 5).

\section{Discussion}

Quality of life is increasingly acknowledged as a valid, appropriate and significant indicator of service need and intervention outcomes in contemporary public health research and practice. Health-related QoL measures, including objective and subjective assessments, are especially useful for evaluating efforts to prevent disabling chronic diseases and assessing their effectiveness [12]. 


\begin{tabular}{|c|c|c|c|c|c|c|c|c|c|c|c|c|c|c|c|c|c|c|c|c|}
\hline \multicolumn{20}{|c|}{ Clinical diagnosis } & \\
\hline \multicolumn{5}{|c|}{ Advanced chronic periodontitis } & \multicolumn{5}{|c|}{ Moderate chronic periodontitis } & \multicolumn{5}{|c|}{ Mild chronic periodontitis } & \multicolumn{5}{|c|}{ Chronic gingivitis } & \\
\hline \multicolumn{20}{|c|}{ Answers } & \\
\hline 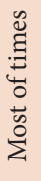 & 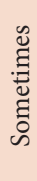 & 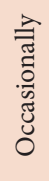 & $\begin{array}{l}\text { ⿹弋工二厶 } \\
\text { ت̇ }\end{array}$ & $\begin{array}{l}\dot{\Delta} \\
\bar{u} \\
\text { z }\end{array}$ & 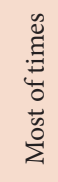 & 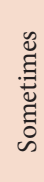 & 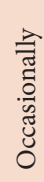 & 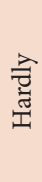 & $\begin{array}{l}\overrightarrow{0} \\
\bar{u}\end{array}$ & 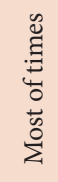 & 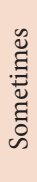 & 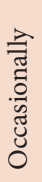 & 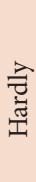 & 崩 & 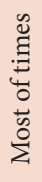 & 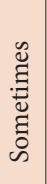 & 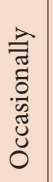 & 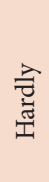 & $\begin{array}{l}\dot{\bar{D}} \\
\dot{z}\end{array}$ & \\
\hline 0 & 3 & 0 & 0 & 0 & 0 & 1 & 1 & 1 & 1 & 1 & 1 & 3 & 4 & 1 & 0 & 0 & 4 & 3 & 12 & Eating \\
\hline \multicolumn{2}{|c|}{$100 \%$} & & & & & & & & & & & & & & & & & & & \\
\hline 0 & 0 & 3 & 0 & 0 & 0 & 0 & 1 & 1 & 2 & 1 & 0 & 1 & 2 & 6 & 1 & 2 & 1 & 0 & 15 & Sleep \\
\hline 0 & 2 & 0 & 1 & 0 & 0 & 1 & 0 & 2 & 1 & 1 & 3 & 2 & 1 & 3 & 0 & 0 & 1 & 3 & 15 & Society avoidance \\
\hline \multirow[t]{2}{*}{1} & 1 & 1 & 0 & 0 & 1 & 1 & \multirow[t]{2}{*}{0} & \multirow[t]{2}{*}{1} & \multirow[t]{2}{*}{1} & \multirow[t]{2}{*}{1} & \multirow[t]{2}{*}{2} & \multirow[t]{2}{*}{4} & \multirow[t]{2}{*}{1} & \multirow[t]{2}{*}{2} & \multirow[t]{2}{*}{0} & \multirow[t]{2}{*}{3} & \multirow[t]{2}{*}{0} & \multirow[t]{2}{*}{5} & \multirow[t]{2}{*}{11} & \multirow{2}{*}{ Anxiety } \\
\hline & & & & & \multicolumn{2}{|c|}{$50 \%$} & & & & & & & & & & & & & & \\
\hline 0 & 3 & 0 & 0 & 0 & 1 & 1 & \multirow[t]{2}{*}{1} & \multirow[t]{2}{*}{0} & \multirow[t]{2}{*}{1} & 0 & 7 & \multirow[t]{2}{*}{1} & \multirow[t]{2}{*}{0} & \multirow[t]{2}{*}{2} & 0 & 4 & \multirow[t]{2}{*}{1} & \multirow[t]{2}{*}{5} & \multirow[t]{2}{*}{9} & \multirow[t]{2}{*}{ Pain } \\
\hline & & & & & & & & & & 70 & & & & & & & & & & \\
\hline
\end{tabular}

Table 5: Affected daily-life activities regarding the clinical diagnosis of the patients

Assessing the consequences of impaired oral health from the patient's perspective has emerged as an important research area [13]. This has led to an increase in the use of patient-centered oral health status measures, primarily attempting to measure the impact of oral health on QoL [14].

The results of the current study showed that only $27.7 \%$ of the patients expressed their gingival health as bad (fair or poor), when using a single question in a simple questionnaire. Additionally, most of them mentioned at least one daily life activity that was affected by some kind of periodontal disease. On the other hand, a considered group of the patients (30.5\%) were satisfied with the situation of gingival health (expressed as "good").

Though the current study encountered a small amount of subjects, which makes any comparison with other studies a little bit difficult, our results were primarily not compatible with those obtained from a comprehensive statistical study in the United States of America [15], where 36\% of adult patients expressed their gingival health as "fair" or "poor".

Surprisingly, the self-assessment of gingival health in our study was increasingly compatible with the current stage of the diagnosed periodontal disease, where $42.1 \%$ of the patients suffering chronic gingivitis expressed their gingival health in general as "excellent", and $100 \%$ of the patients suffering advanced chronic periodontitis expressed their gingival health as "bad". This could be explained that the patient becomes more conscious about the negative signs on his/her teeth and gingiva (e.g. teeth mobility, gingival recession) during the cumulative progress of the periodontal disease.

Many patients (41.1\%) mentioned that the "pain" was most related to the affected daily life activities. Though pain is not one of the critical signs of chronic periodontal diseases, we assume that the patients in our study could have expressed teeth sensitivity caused by gingival recession also as "pain".

Mentioning "anxiety" by $50 \%$ of the patients suffering moderate chronic periodontitis may reflect the internal feelings of them that something bad is going on with the gingival health. Moreover, mentioning "eating" as most daily life activity affected by $100 \%$ of the patients suffering advanced chronic periodontitis reflects the difficulties related to food intake when an advanced periodontal problem is in progress.

Recently, studies regarding oral health-related quality of life in periodontally-compromised patients tried to take the patients' systemic health situation into consideration.

In 2014, Hajian-Tilaki et al. [16] conducted a study to evaluate oral health status and oral health related quality of life in Iranian patients undergoing hemodialysis. They found that hemodialysis patients had a poor oral hygiene and periodontal status, weak attitudes and negligence toward oral health but they were satisfied of their oral health condition and their oral health related quality of life was approximately good.

More recently, Irani et al. (2015) [17] investigated the impact of periodontal status on oral health-related quality of life in patients with and without type 2 diabetes mellitus (T2DM). They found that T2DM does not impact on overall oral health-related quality of life as measured by the oral health impact profile (OHIP)-49, and that chronic periodontitis and gingivitis were associated with poorer oral health-related quality of life in non-diabetic patients, with evidence of improvements following periodontal treatment, but no such effects were observed in patients with diabetes. 
Because the sample of the current study is small when compared to other studies in the field of oral health-related quality of life, it could be considered as a pilot study that strongly needs to be validated before its application in any further studies with a larger sample. However, to our knowledge, this is the first pilot study that tested the oral health-related quality of life of periodontal patients in a Syrian sample, in which a modified questionnaire by Cunha-cruz et al. [11] has been used. The success of testing such experiment could open the gate through more comprehensive statistical studies in the same field.

The current study could not find neither direct nor linear relationship between the actual clinical findings of the patients (i.e. pocket depth measurements) and the affected daily life activities or the self-assessment of gingival health. This was not compatible with the results of (NG and Leung, 2006) [12] who found clear relationship between periodontal disease and some daily life activities. However, this may encourage the researchers and dental health practitioners to improve the conventional methods of diagnosing periodontal diseases by adding specific ways of measuring the disease from the patient's point of view (e.g. selfassessment method).

\section{Conclusion}

The impact of periodontal disease on an individual is usually characterized by clinical parameters such as probing depth and attachment level. However, periodontal disease, through inflammation and destruction of the periodontium, produces a wide range of clinical signs and symptoms, some of which may have a considerable impact on day to day life or life quality [8]. Little is known about this aspect.

Most of the patients who were recruited in this study mentioned at least one daily life activity which was affected by some kind of periodontal disease.

All the patients who were suffering advanced periodontal disease had the feeling that their gingival health was bad. This reflects an acceptable degree of consciousness towards negative changes of the periodontal health.

Failing to find a linear relationship between pocket depth measurements and the patients' self-assessments of gingival health ensures the need of new diagnostic methods that give the patients' expressions of the disease more important role.

Finally, more comprehensive studies should be done to assess the relationship between the critical features of periodontal diseases and daily life activities. This may change the old concept of periodontal disease as a "silent" disease.

\section{References}

1. Dietrich T, Stosch U, Dietrich D, Schamberger D, Bernimoulin JP, et al. (2005) The accuracy of individual self-reported items to determine periodontal disease history. Eur J Oral Sci 113: 135-40.

2. Gilbert AD, Nuttall NM (1999) Self-reporting of periodontal health status. Br Dent J 186: 241-4.

3. Pitiphat W, Garcia RI, Douglass CW, Joshipura KJ (2002) Validation of self-reported oral health measures. J public Health Dent 62: 122-8.

4. Tervonen T, Knuuttila M (1988) Awareness of dental disorders and discrepancy between "objective" and "subjective" dental treatment needs. Community dent Oral Epidemiol 16: 345-8.

5. Blicher B, Joshipura K, Eke P (2005) Validation of self-reported periodontal disease: a systematic review. J Dent Res 84: 881-90.

6. Needleman I, MacGrath C, Floyd P, Biddle A (2004) Impact of oral health on the life quality of periodontal patients. J Clin Periodontol 31: 454-7.

7. Lang NP, Tonetti MS (1996) Periodontal diagnosis in treated periodontitis. J Clin Periodontol 23: 240-50.

8. Locker D (1988) Measuring oral health: a conceptual framework. Community Dent Health 5: 3-18.

9. McGrath C, Bedi R (1999) The value and use of 'quality of life' measures in the primary dental care setting. Prim Dent Care 6: 53-7.

10. Armitage GC (1999) Development of a classification system for periodontal diseases and conditions. Ann Periodontol 4: 1-6.

11. Cunha-Cruz J, Hujoel P, Kressin N. Oral health-related quality of life of periodontal patients. J Periodontal Res 42: 169-76.

12. Ng SK, Leung WK (2006) Oral health-related quality of life and periodontal status. Community Dent Oral Epidemiol 34: 114-22.

13. Buck D, Newton JT (2001) Non-clinical outcome measures in dentistry: publishing trends 1988-98. Community Dent Oral Epidemiol 29: 2-8.

14. Birch S, Ismail A (2002) Patient preferences and the measurement of utilities in the evaluation of dental technologies. J Dent Res 81: 446-50.

15. Dye BA, Tan S, Smith V, Lewis B, Barker L, et al. (2007)Trends in oral health status: United States, 1988-1994 and 1999-2004. Vital and health statistics Series 11, Data from the national health survey 248: 1-92.

16. Hajian-Tilaki A, Oliae F, Jenabian N, Hajian-Tilaki K, Motallebnejad M (2014) Oral Health-related Quality of Life and Periodontal and Dental Health Status in Iranian Hemodialysis Patients. J Contemp Dent Pract 15: 482-90.

17. Irani F, Wassall R, Preshaw P (2015) Impact of periodontal status on oral health-related quality of life in patients with and without type 2 diabetes. J Dent doi: 10.1016/j.jdent.2015.03.001. 


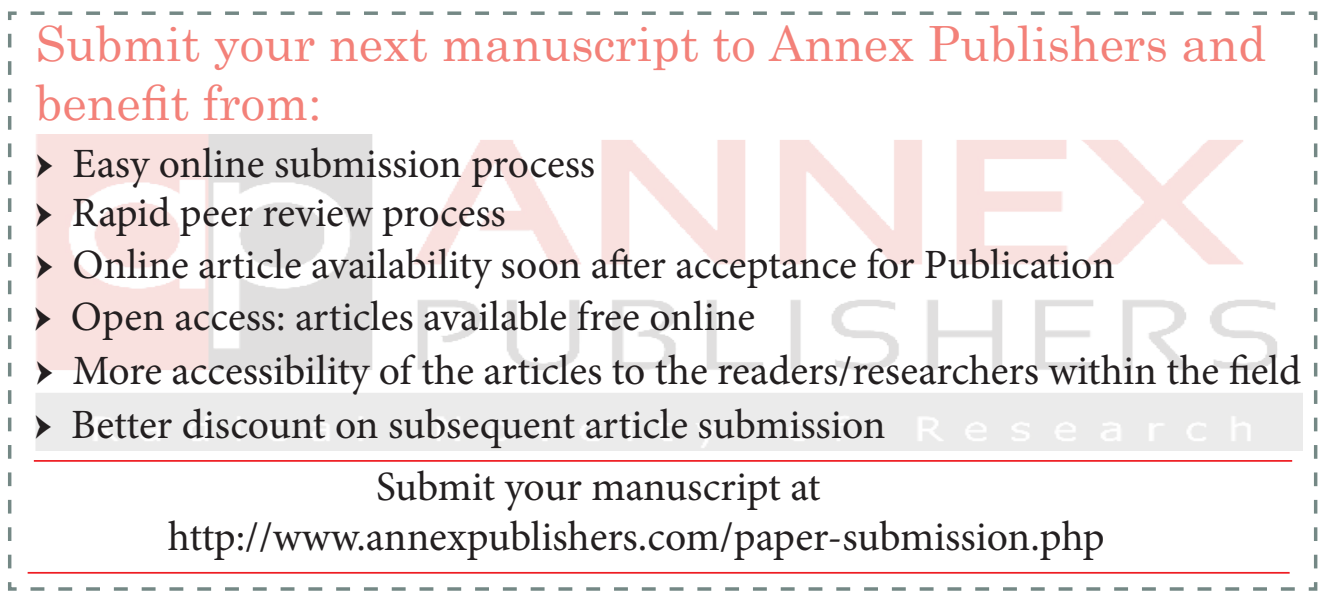

